\title{
Nanny Wermuth, Reinhold Streit (2006): Einführung in statistische Analysen. Fragen beantworten mit Hilfe von Daten
}

\author{
Springer, 372 pp., $€$ 29.95, ISBN 978-3-540-33930-4
}

\section{R. Viertl}

Published online: 10 June 2008

(C) Springer-Verlag 2008

The aim of the book is - as the authors describe in the preface-to introduce into statistical concepts and methods with emphasis on psychological and medical applications. This is made from the viewpoint of interpretation of the statistical results.

Many important statistical analysis methods are explained and good examples are given, especially models for different kinds of dependencies and for development processes. It contains topics which are usually not covered in introductory statistical texts, for example graphical chain models, matched pair design, and the Yatesalgorithm for sequences of numbers. The book contains three main chapters with the following headings: observed variables, random variables, and estimation based on random samples. After this five appendices are contained: Appendix A is titled Exercises which gives many applications on more than 50 pages. Appendix B is on psychological tests. Appendix C contains some mathematical material used in the book. Appendix D explains some basic statistical manipulations and an interesting proof of a sum formula. Appendix E gives tables for the standard normal distribution, the student distribution, and the chi-square distribution. The literature is divided into references for included statistical case studies and general statistical literature. A good index concludes the book. In summary this is an interesting introduction to statistics for psychological and medical research. It is well printed and contains only very few misprintings. Whereas different data are given which are not precise numbers, the problem of fuzzy data is not mentioned. In a second edition it would be good to include statistical methods for fuzzy data because especially in medical research and psychology many data are fuzzy.

R. Viertl (凶)

TU Wien, Wien, Austria

e-mail: R.Viertl@tuwien.ac.at 